\title{
Opportune timing for palliative care specialty designation
}

I t may be a coincidence that palliative care recently came into its own as a subspecialty, but the timing is fortuitous, given the proposed Quebec legislation on medically assisted death and the pending Supreme Court case on euthanasia.

These moves make it imperative to improve education and access to palliative care, says Dr. Doris Barwich, president of Canadian Society of Palliative Care Physicians, who practises in Surrey, British Columbia.

The society is concerned that the Quebec legislation is coming forward as an option in the continuum of end-oflife care, but "at the same time, we're not educating physicians in terms of how to communicate with people at the end of life or how to identify options in pain and symptom management, how to really support people and get teams involved," says Barwich. "The requests for hastened death are usually directly linked to the amount of support that people are receiving. That's a really critical first piece."

The specialty, which was formally recognized by the Royal College of Physicians and Surgeons on Nov. 14, 2013, will be accessible to physicians from many different specialties, including family medicine. The two-year training programs are projected to begin in 2016 at various institutions across Canada. Practising palliative care physicians who want specialty designation will need to document their experience and write an exam. The first exam will be held in 2018. With specialty status, the society will ramp up advocacy, education and research in the field. It also provides recognition for physicians in the specialty.

Dr. Cory Schroeder, co-chair of the Royal College of Physicians and Surgeons of Canada and the College of Family Physicians of Canada Conjoint Advisory Committee on Palliative Medicine adds that "Many of our colleagues didn't recognize the extent of work that [palliative care physicians]

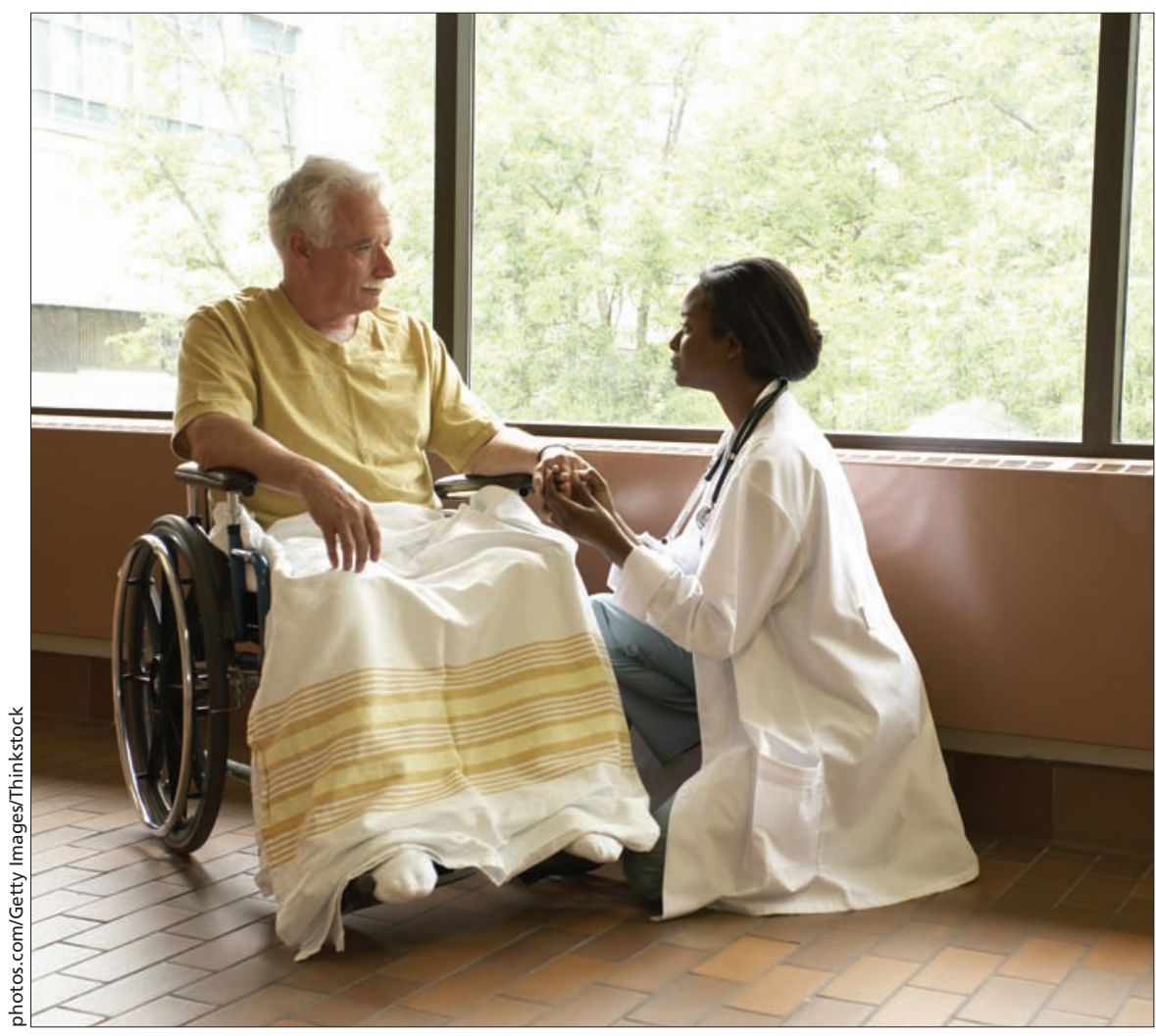

Specialty status will allow palliative care physicians to increase advocacy, education and research in the field.

did, and didn't really understand or value the expertise that is held in physicians that practice palliative care full time."

In addition to education, access is also a top-of-mind issue for the new specialty. Availability of palliative care, particularly in rural and remote areas, remains suboptimal and in some places, nonexistent.

The 2005 senate committee report, Still Not There. Quality End-of-Life Care: A Progress Report, stated that every Canadian has the right to excellent palliative care, Schroeder points out. "Right now, it's maybe $20 \%$ of the population that gets it. So [specialty status] is a way to move things forward."

Barwich hopes that palliative care being a specialty will result in the training of more physicians who can serve as mentors and educators in areas where services are spotty.
These are important steps, but Barwich is concerned about how the specialty, as well as the doctor-patient relationship, will be affected if the Quebec legislation is passed.

"The practice of palliative care needs to be quite separate from what happens in Quebec.... .We are concerned that it may erode trust if you don't know if what your MD is suggesting is a subtle form of euthanasia or is in fact good palliative care."

Barwich sees specialty status as an essential part of the best-case scenario for Canada in the changing landscape of end-of-life care. "If [medically assisted death] is legalized, the boundary lines must be very clear about how it is provided, by whom, and that it is not part of palliative care." - Gordon Giddings, CMAJ

CMAJ 2014. DOI:10.1503/cmaj.109-4744 